\title{
ANALISIS DAN PERANCANGAN SISTEM INFORMASI FASILITAS KOLABORASI DAN MONITORING PENYUSUNAN PERANGKAT DIKLAT DI PUSDIKLAT MINERAL DAN BATUBARA
}

\author{
Yusup Jauhari Shandi \\ Sekolah Tinggi Manajemen Informatika dan Komputer LIKMI \\ Jl. Ir. H. Juanda Bandung 40132 \\ E-mail : ujshandi@gmail.com
}

\begin{abstract}
ABSTRAK
Peningkatan kualitas sumber daya manusia perlu dilakukan secara terencana, terarah, dan berkesinambungan dalam rangka meningkatkan kemampuan dan profesionalisme. Sasaran dari pengembangan kualitas sumber daya manusia adalah untuk meningkatkan kinerja operasional sumber daya manusia dalam melaksanakan tugas-tugas. Selain itu, kualitas sumberdaya manusia yang tinggi akan bermuara pada lahirnya komitmen yang kuat dalam penyelesaian tugas-tugas rutin sesuai tanggung jawab dan fungsinya masing-masing secara lebih efisien, efektif, dan produktif. Dalam peningkatan kualitas sumber daya manusia tersebut perlu diselenggarakan pendidikan dan pelatihan.

Penyusunan perangkat diklat yang tepat waktu dan berkualitas sangat mendukung kegiatan diklat berjalan dengan baik. Untuk lebih meningkatkan kualitas dan ketepatan waktu proses penyusunan perangkat diklat yang telah ada maka dibuatlah Sistem Aplikasi "Fasilitas Kolaborasi dan monitoring Penyusunan Perangkat Diklat"
\end{abstract}

\section{Kata kunci : kolaborasi, monitoring, perangkat diklat}

\section{PENDAHULUAN}

Pendidikan dan pelatihan (Diklat) di sektor geologi, mineral dan batubara yang dilaksanakan oleh Pusat Pengembangan Sumber Daya Manusia Geologi, Mineral, dan Batubara merupakan upaya untuk meningkatkan pengetahuan, keterampilan, dan sikap (KSA) baik aparatur, tenaga industri maupun masyarakat (Kepmen ESDM Nomor 1453.K/29/MEM/2000). Suatu Diklat akan berjalan dengan baik jika memiliki landasan pokok yang jelas sebagaimana tertuang dalam perangkat diklat baik kurikulum, modul, materi uji maupun pedoman kediklatan.

Salah satu pilar kebijakan pengembangan sumber daya manusia sektor energi dan sumber daya mineral yang kompeten dan profesional dengan melakukan penyelenggaraan diklat berbasis kompetensi. Penyelenggaraan diklat dan dikjar berbasis kompetensi melibatkan unsur penyelenggaraan dan dukungan sarana dan prasarana yang memadai sehingga tujuan dari diklat dan dikjar dapat tercapai dengan sempurna. Sarana dan prasarana sebagai bagian integral dari keseluruhan kegiatan pembelajaran di kegiatan pendidikan dan pelatihan mempunyai fungsi dan peran dalam pencapaian kegiatan pembelajaran sesuai kurikulum satuan pendidikan. Agar pemenuhan sarana dan prasarana tepat guna dan berdaya guna (efektif dan efisien), diperlukan suatu analisis kebutuhan yang tepat di dalam perencanaan pemenuhannya.

Salah satu program dalam menyiapkan sarana kediklatan adalah penyusunan perangkat kediklatan sebagai pendukung keberhasilan pelaksanaan diklat dari segi sistem, 
perangkat kediklatan merupakan komponen yang tak terpisahkan dari keberhasilan pelaksanaan program diklat berbasis kompetensi. Dengan adanya perangkat diklat maka suatu diklat memiliki acuan dan ukuran agar pelaksanaan diklat sesuai dengan rencana yang telah ditetapkan. Tanpa standar kediklatan, maka program diklat tidak dapat dilaksanakan secara baik dan benar.

Perangkat kediklatan adalah meliputi kurikulum/silabi, modul, materi uji, dan pedoman diklat. Penyusunan perangkat kediklatan tersebut didasarkan atas Standar Kompetensi/ Standar Kompetensi Khusus. Penyusunan perangkat diklat ini melibatkan Kolaborator (subbidang Standardisasi), Widyaiswara dan Narasumber yang terkadang untuk mengumpulkan ketiga unsur tersebut terkendala waktu, lokasi dan tempat, untuk dengan menggunakan kemajuan teknologi informasi dan komunikasi maka disusunlah sistem aplikasi "Fasilitas Kolaborasi dan Monitoring Penyusunan Perangkat Diklat" yang memungkinkan para pihak untuk berkolaborasi kapan saja dan di mana saja.

Pengembangan Sistem Informasi Fasilitas Kolaborasi dan Monitoring Penyusunan Perangkat Diklat adalah aplikasi baru yang dapat menunjang pelaksanaan kegiatan penyusunan dan pengembangan perangkat diklat menjadi lebih efektif dan efisien. Aplikasi ini dilengkapi fitur file sharing, shared calendar, group conversation, dan project management tools berbasis website. Pembuatan sistem ini didasari oleh analisis terhadap proses penyusunan perangkat diklat yang cenderung penyelesaiannya di akhir tahun anggaran. Diharapkan dari penggunaan aplikasi ini diperoleh informasi dan proses penyusunan standar perangkat diklat yang cepat, terpadu, akurat, transparan, dan akuntabel sehingga dapat mempercepat waktu penyusunan sesuai jadwal yang telah ditetapkan dan meningkatkan kualitas perangkat diklat yang disusun.

\section{MAKSUD, TUJUAN, DAN MANFAAT}

Pedoman penyusunan perangkat diklat menggunakan "Fasilitas Kolaborasi dan Monitoring Penyusunan Perangkat Diklat" disusun dengan maksud sebagai acuan dalam menyusun perangkat kediklatan dengan menggunakan teknologi informasi dan komunikasi di bidang geologi, mineral, dan batubara pada Pusat Pengembangan Sumber Daya Manusia Geologi, Mineral, dan Batubara.

Tujuan penyusunan pedoman penyusunan perangkat diklat menggunakan "Fasilitas Kolaborasi dan Monitoring Penyusunan Perangkat Diklat" ini adalah tersusunnya perangkat kediklatan untuk bidang geologi, mineral, dan batubara sesuai dengan kualitas dan waktu yang telah direncanakan.

Manfaat dari adanya pedoman tata cara penyusunan perangkat diklat menggunankan "Fasilitas Kolaborasi dan Monitoring Penyusunan Perangkat Diklat" ini adalah:

a. Pelaksana, Widyaiswara dan Narasumber dapat saling berkoordinasi dalam penyusunan perangkat diklat kapan saja dan di mana saja;

b. Dapat digunakan sebagai pengingat kegiatan rapat offline, dan waktu pengumpulan penyusunan perangkat diklat;

c. File-file penyusunan perangkat diklat yang mutakhir terdapat di server, sehingga dapat diakses lebih mudah;

d. Kemajuan penyusunan perangkat diklat dapat terpantau dengan lebih mudah;

e. Dapat digunakan sebagai sarana penyimpanan data setiap kegiatan penyusunan perangkat diklat.

\section{KOLABORASI}

Kolaborasi adalah "a purposive relationship". (Schrage, 1995 : 29). Menurut Schrage (1995:29) dengan berkolaborasi : 
a. Kita dapat memecahkan masalah yang sebelumnya mungkin tidak bisa kita selesaikan sendiri

b. Menciptakan sesuatu karena setiap individu memiliki jalan pikiran yang unik sehingga ada kemungkinan bahwa mereka bisa menemukan hal baru dari sudut pandang yang berbeda

c. Menemukan sesuatu di dalam sejumlah hambatan

Walaupun kolaborasi menawarkan solusi yang menggiurkan, ada juga hambatan dalam berkolaborasi seperti yang dikutip dari Schrage ;
a. Keahlian
b. Waktu
c. Biaya
d. Kompetisi
e. Kearifan konvensional

\section{LINGKUNGAN SISTEM}

Secara keseluruhan sistem ini akan berfokus pada pengelolaan kegiatan penyusunan perangkat diklat dalam kurun waktu satu tahun, mulai dari penetapan kegiatan yang akan dilakukan, pembagian Person in Charge (PIC) serta kontributor untuk setiap kegiatan, hingga pemantauan atau monitoring dari setiap kegiatan. Pada Gambar 1 ditampilkan deskripsi singkat mengenai lingkup sistem Fasilitas Kolaborasi dan Monitoring Penyusunan Perangkat Diklat yang akan dikembangkan.

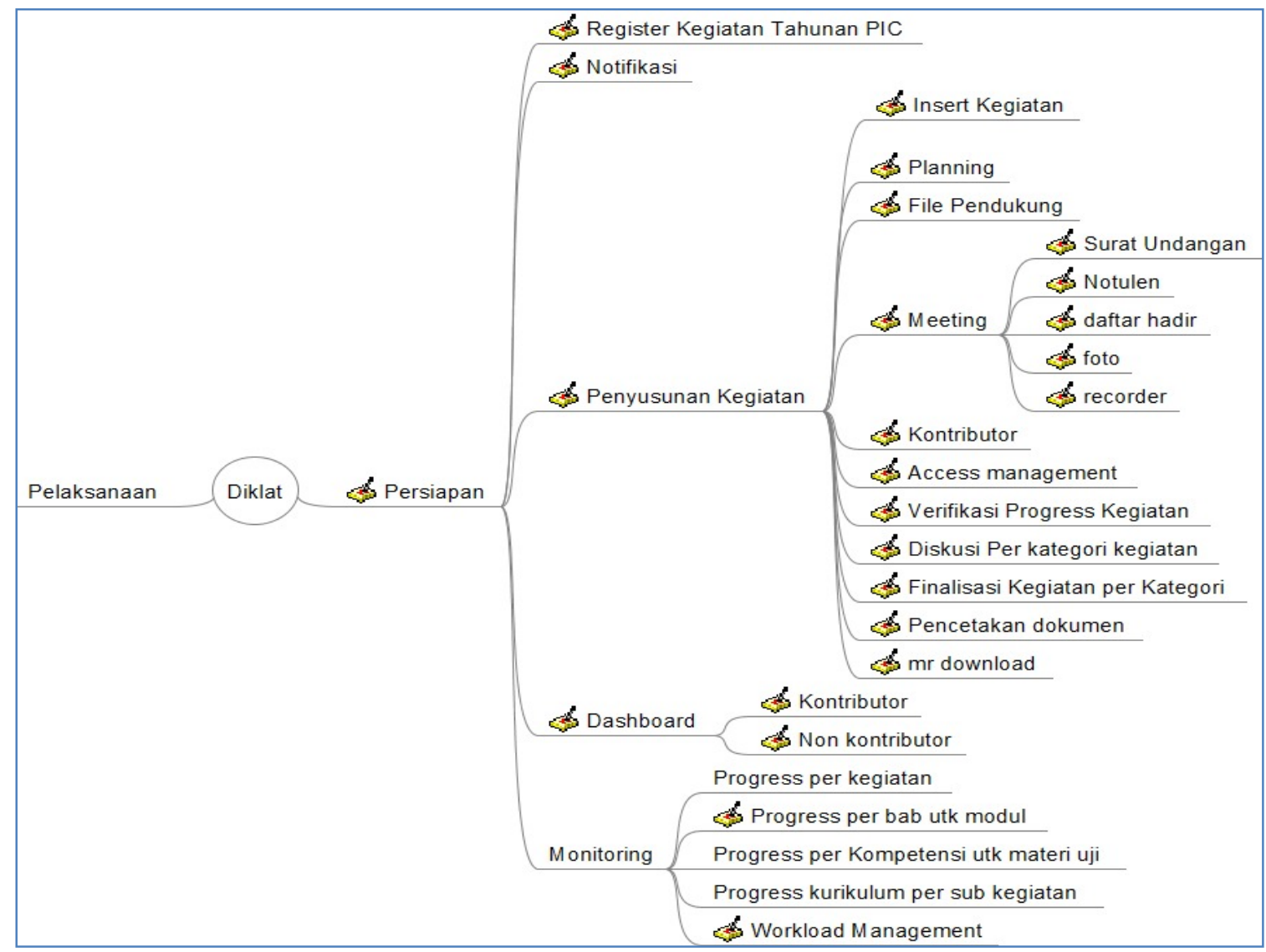

Gambar 1

Lingkup sistem Fasilitas Kolaborasi dan Monitoring Penyusunan Perangkat Diklat 


\section{OUTPUT APLIKASI FASILITAS KOLABORASI DAN MONITORING PENYUSUNAN PERANGKAT DIKLAT}

Pada Aplikasi Fasilitas Kolaborasi dan Monitoring Penyusunan Perangkat Diklat, ada 6 keluaran yang terdiri dari:
a. Kurikulum Diklat
b. Modul Diklat
c. Materi Uji Diklat
d. Pedoman Diklat
e. Laporan Kegiatan
f. Monitoring progress kegiatan

\section{TOPOLOGI DAN INFRASTRUKTUR}

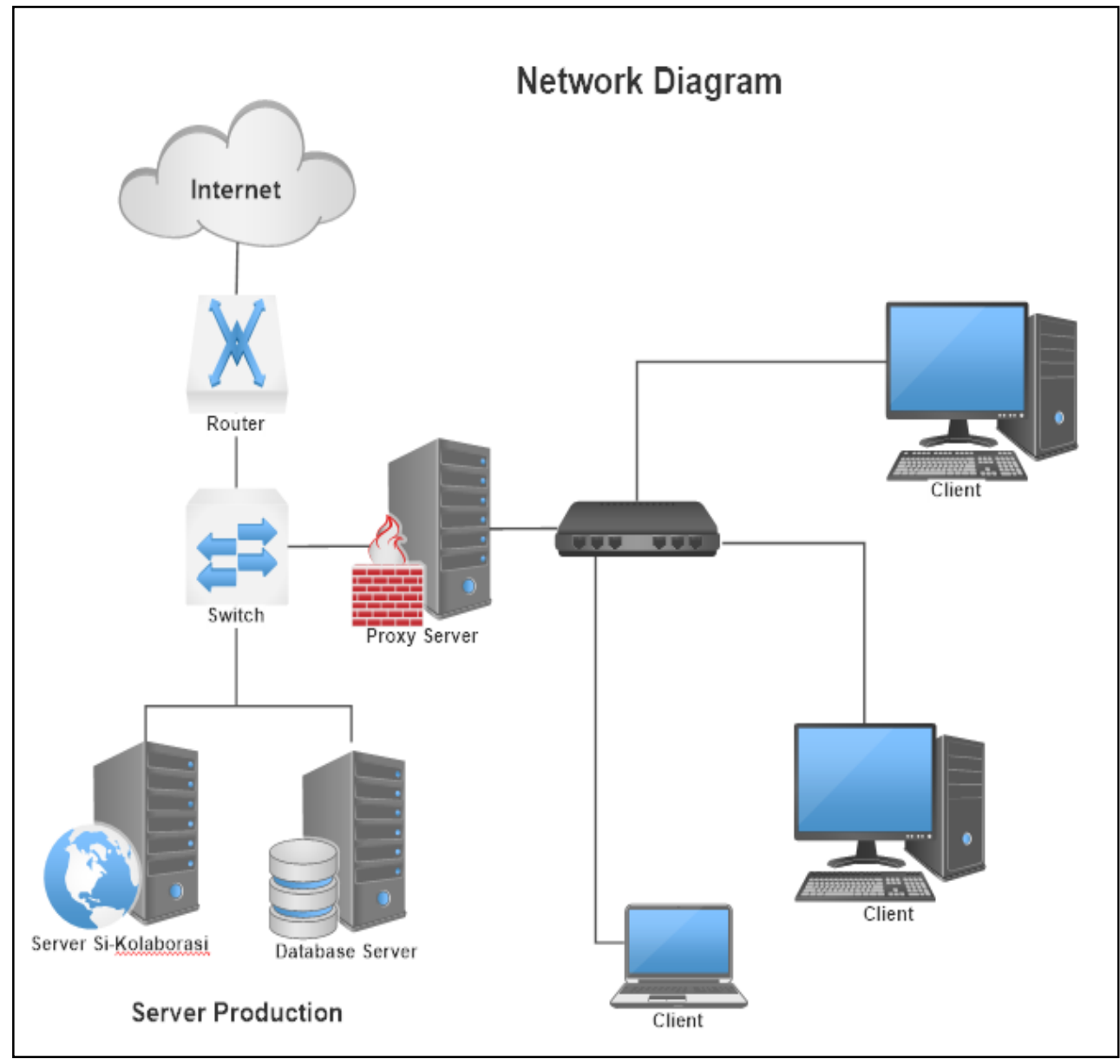

Gambar 2

Topologi dan Infrastruktur Sistem 


\section{KEBUTUHAN FUNGSIONAL}

Kebutuhan fungsional sistem fasilitas kolaborasi dan monitoring penyusunan perangkat diklat digambarkan dalam use case diagram berikut :

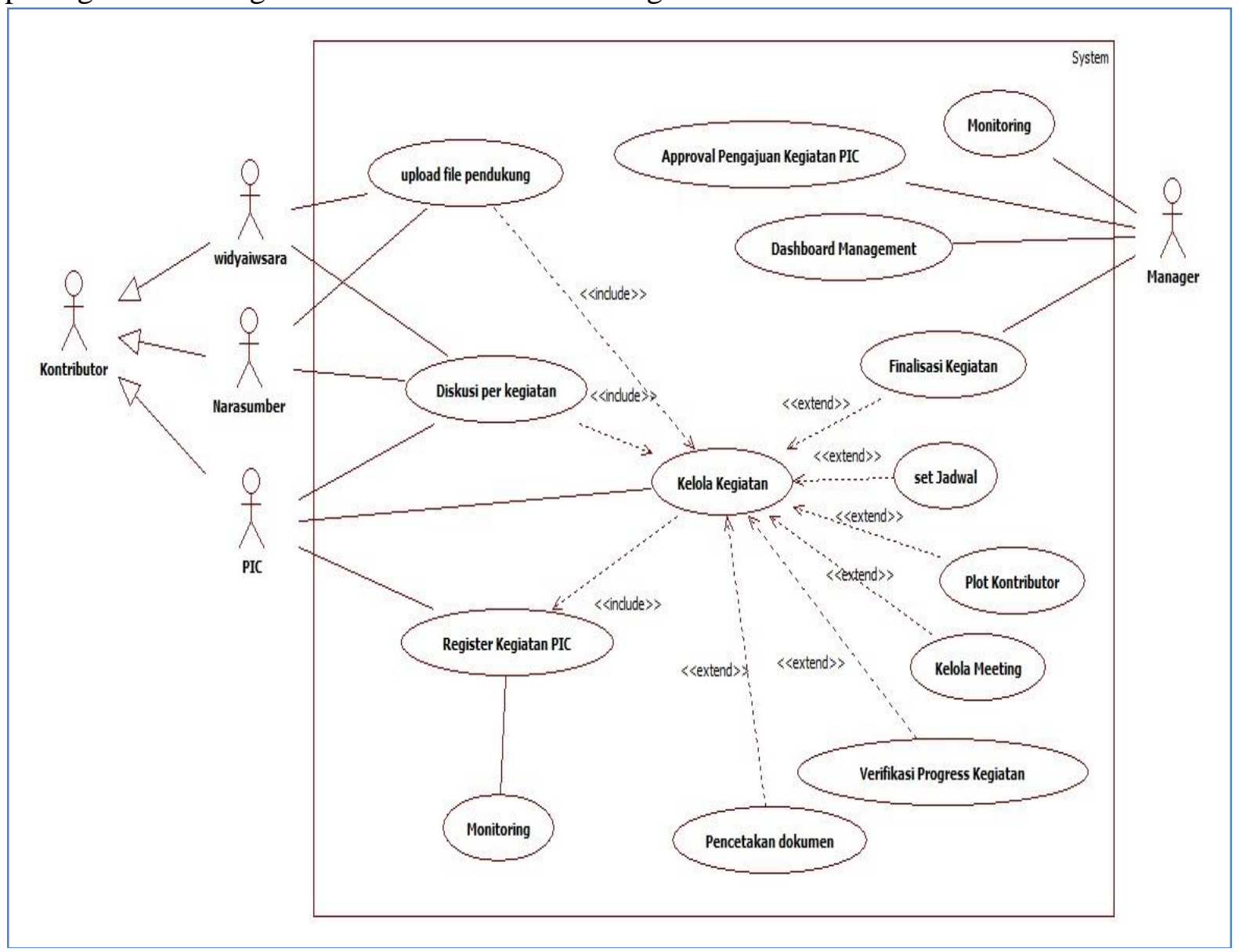

Gambar 3

Diagram Use Case

Berikut adalah penjelasan dari aktor serta use case Fasilitas Kolaborasi dan Monitoring Penyusunan Perangkat Diklat ini, yaitu:

a. Aktor

1) Kontributor, dimana aktor ini merupakan hasil generalisasi dari PIC, Widsyaiswara, Narasumber

2) Manager, pihak yang bertanggungjawab serta memantau proses penyusunan perangkat diklat

b. Use Case

1) Register kegiatan PIC, proses pengajuan keterlibatan pada sebuah kegiatan persiapan penyusunan perangkat diklat

2) Approval pengajuan kegiatan PIC, proses melakukan persetujuan terhadap sebuah proses register kegiatan yang dilakukan PIC

3) Kelola kegiatan, proses menambah sebuah kegiatan penyusunan perangkat diklat, dikelompokkan menjadi 4 kategori kegiatan yaitu : penyusunan kurikulum, penyusunan modul, penyusunan materi uji, penyusunan pedoman

4) Set Jadwal, proses menentukan jadwal sebuah kegiatan akan dilaksanakan

5) Plot kontributor, proses menentukan kontributor (narasumber, widyaiswara) yang terlibat dalam sebuah kegiatan per kategori kegiatan 
6) Kelola Meeting, proses pengarsipan dokumen meeting seperti : surat undangan, notulen, daftar hadir, foto serta rekaman audio meeting.

7) Diskusi Per kegiatan, proses diskusi dalam sebuah kegiatan, dimana diskusi tersebut hanya melibatkan kontributor yang terkait pada kegiatan tersebut

8) Upload file pendukung, proses pengunggahan file-file hasil pekerjaan dari kontributor (narasumber, widyaiswara) per kegiatan yang menjadi tanggungjawab dari kontributor tersebut

9) Verifikasi progress kegiatan, proses (checklist) setiap kegiatan sudah selesai dikerjakan atau belum, dilakukan PIC. Proses verifikasi dengan asumsi PIC telah melakukan pengecekan output/file pendukung dari kegiatan tersebut.

10) Finalisasi kegiatan, Approval / tidak (ditambahkan catatan ketika laporan ditolak) bahwa kegiatan ini sudah selesai di list kegiatan adalah : "Laporan Kegiatan". Aktualnya terlebih dahulu dilakukan pemeriksaan, validasi oleh manajemen

11) Pencetakan dokumen, Proses akhir kegiatan oleh PIC untuk pencapaian progress $100 \%$ (kegiatan selesai)

4.

Sebagai bahan analisis secara garis besar bisa digambarkan diagram class pada Gambar

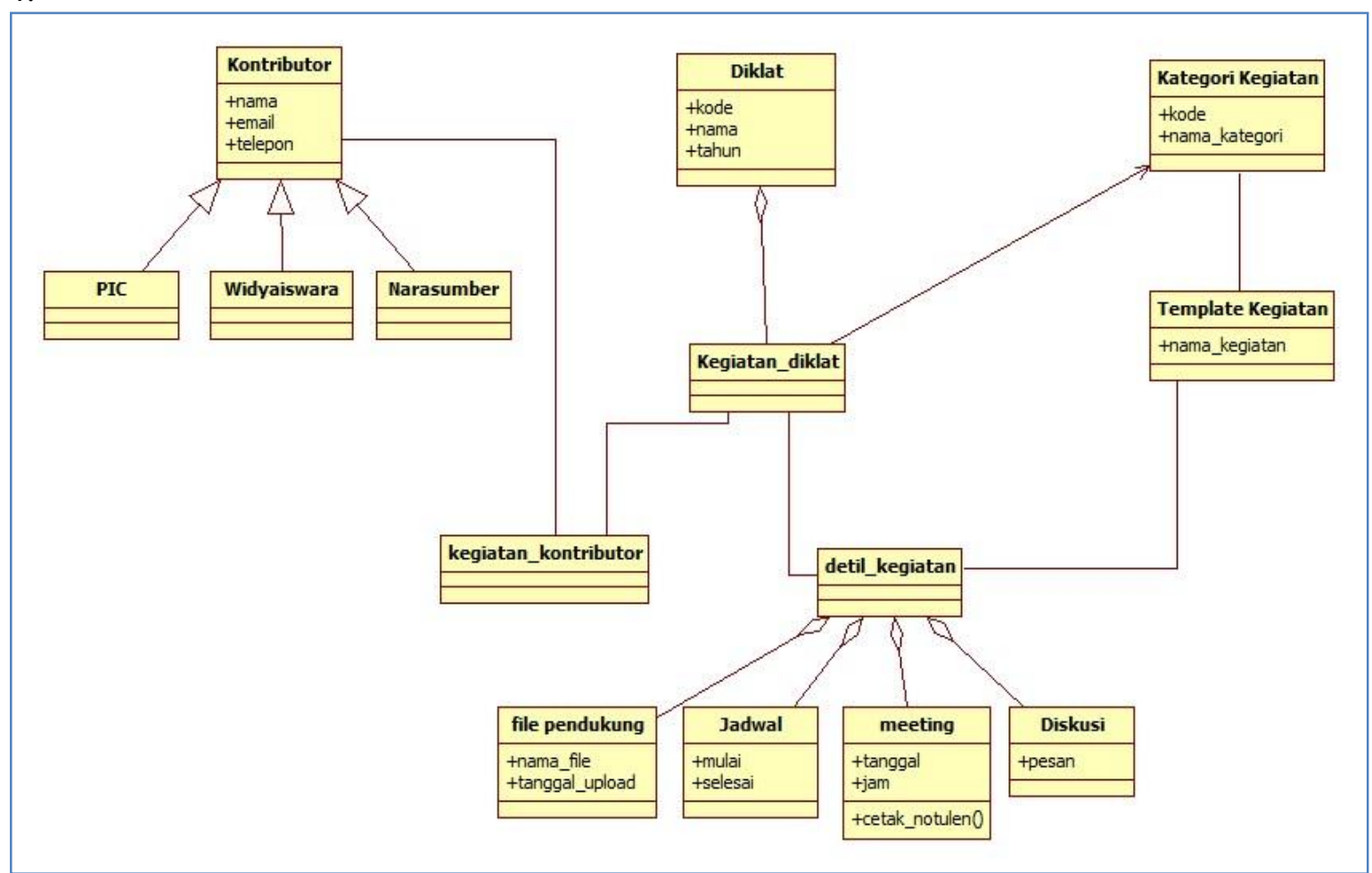

Gambar 4

Diagram Class

\section{KESIMPULAN}

Sistem aplikasi "Fasilitas Kolaborasi dan Monitoring Penyusunan Perangkat Diklat" memungkinkan para penyusun perangkat diklat yang terdiri dari kolaborator (staf subbidang Standardisasi), penyusun (widyaiswara) dan narasumber dari luar PPSDM Geominerba dapat menyusun perangkat diklat dimana saja dan kapan saja, sehingga diharapkan penyusunan perangkat diklat dapat lebih berkualitas dan tepat waktu. 


\section{DAFTAR PUSTAKA}

[1] Michael Schrage, No More Teams!: Mastering the Dynamics of Creative Collaboration, 1995

[2] Keputusan Menteri ESDM Nomor 18 Tahun 2010 dan Kepmen ESDM Nomor 1453.K/29/MEM/2000 tentang Tugas Fungsi Aparatur Pemerintah Pusat dan Daerah Pada Subsektor Pertambangan Mineral Dan Batubara 